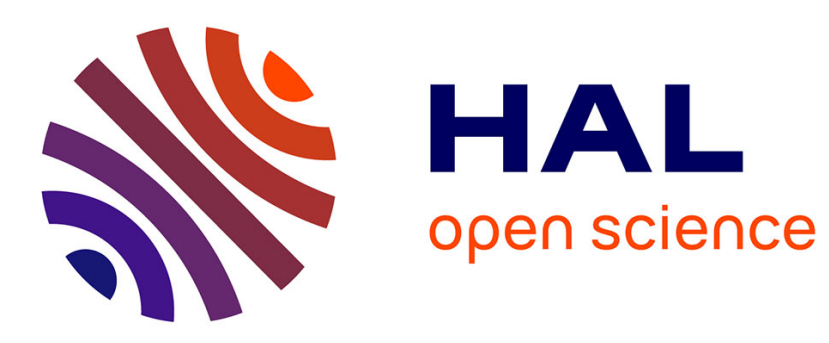

\title{
The role of efflux pumps in macrolide resistance in complex
}

\author{
Liliana Rodrigues, Daniela Sampaio, Isabel Couto, Diana Machado, Winfried \\ V. Kern, Leonard Amaral, Miguel Viveiros
}

\section{- To cite this version:}

Liliana Rodrigues, Daniela Sampaio, Isabel Couto, Diana Machado, Winfried V. Kern, et al.. The role of efflux pumps in macrolide resistance in complex. International Journal of Antimicrobial Agents, 2009, 34 (6), pp.529. 10.1016/j.ijantimicag.2009.07.010 . hal-00556359

\section{HAL Id: hal-00556359 https://hal.science/hal-00556359}

Submitted on 16 Jan 2011

HAL is a multi-disciplinary open access archive for the deposit and dissemination of scientific research documents, whether they are published or not. The documents may come from teaching and research institutions in France or abroad, or from public or private research centers.
L'archive ouverte pluridisciplinaire HAL, est destinée au dépôt et à la diffusion de documents scientifiques de niveau recherche, publiés ou non, émanant des établissements d'enseignement et de recherche français ou étrangers, des laboratoires publics ou privés. 


\section{Accepted Manuscript}

Title: The role of efflux pumps in macrolide resistance in Mycobacterium avium complex

Authors: Liliana Rodrigues, Daniela Sampaio, Isabel Couto, Diana Machado, Winfried V. Kern, Leonard Amaral, Miguel Viveiros

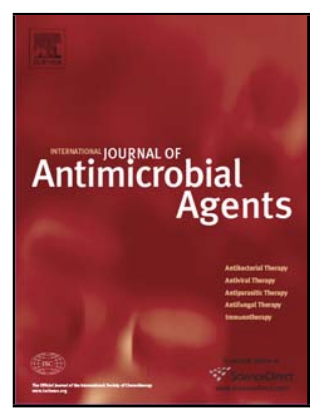

PII: S0924-8579(09)00365-3

DOI:

Reference: doi:10.1016/j.ijantimicag.2009.07.010

To appear in: International Journal of Antimicrobial Agents

Received date: 20-7-2009

Accepted date: $\quad$ 22-7-2009

Please cite this article as: Rodrigues L, Sampaio D, Couto I, Machado D, Kern WV, Amaral L, Viveiros M, The role of efflux pumps in macrolide resistance in Mycobacterium avium complex, International Journal of Antimicrobial Agents (2008), doi:10.1016/j.ijantimicag.2009.07.010

This is a PDF file of an unedited manuscript that has been accepted for publication. As a service to our customers we are providing this early version of the manuscript. The manuscript will undergo copyediting, typesetting, and review of the resulting proof before it is published in its final form. Please note that during the production process errors may be discovered which could affect the content, and all legal disclaimers that apply to the journal pertain. 


\section{The role of efflux pumps in macrolide resistance in} Mycobacterium avium complex

Liliana Rodrigues a,b, Daniela Sampaio a, Isabel Couto ${ }^{\text {a,c }}$, Diana Machado a,

Winfried V. Kern ${ }^{\mathrm{d}, \mathrm{e}}$, Leonard Amaral ${ }^{\mathrm{a}, \mathrm{b}, \mathrm{e}}$, Miguel Viveiros ${ }^{\mathrm{a}, \mathrm{e}, \star}$

a Unit of Mycobacteriology, Instituto de Higiene e Medicina Tropical,

Universidade Nova de Lisboa (IHMT/UNL), Rua da Junqueira 96, 1349-008

Lisboa, Portugal

b UPMM, Instituto de Higiene e Medicina Tropical, Universidade Nova de Lisboa (IHMT/UNL), Rua da Junqueira 96, 1349-008 Lisboa, Portugal

${ }^{c}$ Centro de Recursos Microbiológicos (CREM), Faculdade de Ciências e Tecnologia, Universidade Nova de Lisboa, 2829-516 Caparica, Portugal

${ }^{d}$ Center for Infectious Diseases and Travel Medicine, University Hospital, Hugstetter Strasse 55, D-79106 Freiburg, Germany

${ }^{\text {e }}$ COST ACTION BM0701 (ATENS)

ARTICLE INFO

Article history:

Received 20 July 2009

Accepted 22 July 2009

Keywords:

Mycobacterium avium complex

Macrolide resistance 
Efflux pumps

Efflux pump inhibitors

Phenothiazines

Real-time fluorometry

* Corresponding author. Tel.: +351 21365 2652; fax: +351 213632105 .

E-mail address: mviveiros@ihmt.unl.pt (M. Viveiros). 


\section{ABSTRACT}

Mycobacterium avium complex (MAC) is clinically important since it can cause severe infections in acquired immune deficiency syndrome (AIDS) patients and other immunocompromised individuals. Use of the macrolides clarithromycin and azithromycin has improved the outcome of MAC infections, but therapeutic failure is still a major problem. In this work, we studied efflux pump activity in MAC clinical strains and evaluated the contribution of active efflux to macrolide resistance. Eighteen clinical strains isolated from AIDS patients were evaluated for macrolide resistance in the presence and absence of the efflux pump inhibitors (EPIs) thioridazine, chlorpromazine and verapamil. The efflux activity of these strains was then assessed by a semi-automated fluorometric method that detects extrusion of ethidium bromide (EtBr), a known efflux pump substrate. Resistance to clarithromycin was significantly reduced in the presence of thioridazine, chlorpromazine and verapamil. The same EPIs were effective in decreasing the efflux of EtBr from MAC cells. Moreover, increased retention of $\left[{ }^{14} \mathrm{C}\right]$-erythromycin in the presence of these EPIs further demonstrated that active efflux contributes to MAC resistance to macrolides. This study demonstrates that efflux pumps play an important role in MAC resistance to antibiotics. 


\section{Introduction}

Mycobacterium avium complex (MAC) comprises a heterogeneous group of environmental mycobacteria whose clinical relevance has acquired greater significance in recent decades because it causes severe infections in acquired immune deficiency syndrome (AIDS) patients and other immunocompromised individuals [1-4]. The classic definition of MAC includes the genetically distinct species Mycobacterium avium and Mycobacterium intracellulare [5]. Mycobacterium avium is more prevalent in clinical and environmental samples and is mainly responsible for disseminated MAC disease in human immunodeficiency virus (HIV) patients, whereas $M$. intracellulare is an important contributor to MAC-associated pulmonary infections in immunocompetent or non-HIV patients $[2,6-8]$.

MAC infections are difficult to treat owing to the intrinsic multidrug resistance of the organism, which is assumed to be a consequence of decreased permeability of the cell wall, mainly due to the composition of the thick arabinogalactan-peptidoglycan-mycolic acid layer that is present in all mycobacteria. However, exclusively in MAC strains, this layer is surrounded by a second electron-dense layer of serovar-specific glycopeptidolipids [5]. Thus, the wide range of resistance shown by MAC isolates to most antimicrobial drugs has been ascribed to the composition of its unique cell wall, the integrity of which, when affected, results in increased susceptibility to a variety of drugs $[2,3,9,10]$. The only antimicrobial agents for which a correlation has been demonstrated between in vitro susceptibility results and clinical outcome in controlled clinical trials are the macrolides clarithromycin and azithromycin. 
Because susceptibility to clarithromycin predicts susceptibility to azithromycin, the Clinical and Laboratory Standards Institute (CLSI) guidelines [11] state that clarithromycin should be the only drug routinely evaluated for activity against MAC. There are no CLSI interpretive guidelines for other drugs since in vitro results are not predictive of clinical outcome and may be misleading [11]. Nevertheless, other drugs such as rifabutin, ethambutol, amikacin, clofazimine, linezolid and the fluoroquinolones are relatively effective in controlling MAC bacteraemia as long as they are able to reach their internal target and the target has not mutated $[3,10]$.

It is now known that efflux pumps contribute to intrinsic resistance of mycobacteria to antibiotics. Moreover, when these efflux pumps are overexpressed they extrude a wide variety of chemically and structurally unrelated noxious compounds from the cell, thereby preventing them from reaching their intended targets [12-16]. Although overexpressed activity of efflux pumps may account for multidrug-resistant (MDR) phenotypes of some MAC and Mycobacterium tuberculosis clinical strains, evidence in support of this possibility is essentially absent.

The activity of efflux pumps in M. tuberculosis responsible for induced high-level resistance to isoniazid can be inhibited by efflux pump inhibitors (EPIs) such as reserpine $[12,13,17]$. On the other hand, intrinsic efflux activity of MAC strains has been shown to be inhibited by the phenothiazines thioridazine and chlorpromazine as well as by verapamil $[18,19]$. 
We have previously demonstrated the presence of an intrinsic efflux system in M. avium ATCC $25291^{\top}$ with the aid of a semi-automated fluorometric method [19]. The study described here uses the same methodology to detect efflux pump activity in MAC clinical strains and correlates this activity with a macrolide-resistant phenotype.

\section{Materials and methods}

\subsection{Materials}

Middlebrook 7H9 broth and oleic acid-albumin-dextrose-catalase (OADC) supplement were purchased from Difco (Detroit, MI). Ethidium bromide (EtBr), glucose, phosphate-buffered solution (PBS), potassium phosphate, lithium chloride, chlorpromazine, thioridazine, verapamil and erythromycin were purchased from Sigma-Aldrich Química SA (Madrid, Spain). Clarithromycin was obtained from Abbott Laboratories (Abbott Park, IL). [N-Methyl- $\left.{ }^{14} \mathrm{C}\right]-$ erythromycin and the liquid scintillation cocktail ULTIMA GOLD F were purchased from PerkinElmer (Waltham, MA). All solutions were prepared on the day of the experiment.

\subsection{Bacteria}

The following MAC strains were used in this study: the reference strains $M$. avium subsp. avium ATCC $25291^{\top}$ and $M$. intracellulare ATCC $13950^{\top} ; M$. avium 104, a common MAC representative whose genome is sequenced; and 17 clinical strains isolated from respiratory specimens from AIDS patients, received in our laboratory from hospitals of the Greater Lisbon area for routine 
mycobacterial isolation and identification. All specimens were processed by the conventional mycobacteriological $\mathrm{NaOH}-\mathrm{NALC}$ method [20] and aliquots were collected for acid-fast staining (Ziehl-Neelsen) and inoculation of MGIT tubes of the BACTEC ${ }^{T M}$ MGIT $^{\text {TM }} 960$ system (Becton-Dickinson Diagnostic Instrument Systems, Towson, MD). MAC strains present in full-grown cultures were identified as M. avium or M. intracellulare by the AccuProbe ${ }^{\circledR}$ system (GenProbe Inc., San Diego, CA) according to the manufacturer's instructions. For the following studies the strains were grown at $37^{\circ} \mathrm{C}$ in Middlebrook $7 \mathrm{H} 9$ broth or Middlebrook $7 \mathrm{H} 11$ solid media, both supplemented with $10 \%$ OADC.

\subsection{Determination of minimum inhibitory concentrations (MICs)}

MICs for the EPIs thioridazine, chlorpromazine and verapamil and for the antibiotics clarithromycin and erythromycin, alone and in the presence of an EPI, were determined by the broth microdilution method according to CLSI guidelines [11]. Briefly, MAC strains were grown in 7H9/OADC medium at $37^{\circ} \mathrm{C}$ to an optical density at $600 \mathrm{~nm}\left(\mathrm{OD}_{600}\right)$ of 0.8 . Bacterial cultures were diluted with PBS to McFarland No. 0.5 standard and the inoculum prepared with an aliquot of the suspension was diluted to $1: 100$. Aliquots of $0.1 \mathrm{~mL}$ of the inoculum were transferred to wells of a 96-well plate containing $0.1 \mathrm{~mL}$ of 7H9/OADC medium with two-fold serial dilutions of each agent. The inoculated plates were incubated at $37^{\circ} \mathrm{C}$ until growth in the agent-free control well was evident (5-7 days). The MIC was defined as the lowest concentration of compound that inhibited visible growth. 


\subsection{Ethidium bromide efflux assay by a semi-automated fluorometric method}

EtBr extrusion from MAC cells was assessed by a semi-automated fluorometric method as described previously [19,21]. Briefly, mycobacterial cells were grown in $7 \mathrm{H} 9 / \mathrm{OADC}$ medium at $37^{\circ} \mathrm{C}$ until an $\mathrm{OD}_{600}$ of 0.8 . The culture was centrifuged at $13000 \mathrm{rpm}$ for $3 \mathrm{~min}$, the supernatant was discarded and the pellet was washed once and re-suspended in PBS. After adjusting the $\mathrm{OD}_{600}$ to 0.4 , mycobacteria were exposed to conditions that promoted maximum accumulation of $\mathrm{EtBr}$ : $\mathrm{EtBr}$ at $0.5 \times \mathrm{MIC}$ for each strain; no glucose; presence of verapamil at $0.5 \times \mathrm{MIC}$; and incubation at $25^{\circ} \mathrm{C}$ for $60 \mathrm{~min}$. EtBr-loaded cells were centrifuged at $13000 \mathrm{rpm}$ for $3 \mathrm{~min}$ and re-suspended in EtBr-free PBS. After adjusting the $\mathrm{OD}_{600}$ to 0.4 , glucose was added at a final concentration of $0.4 \%$, aliquots of $0.095 \mathrm{~mL}$ were transferred to $0.2 \mathrm{~mL}$ microtubes and EPIs were added. Fluorescence was measured in a real-time Rotor-Gene ${ }^{\mathrm{TM}} 3000$ thermocycler (Corbett Research, Sydney, Australia) using $530 \mathrm{~nm}$ band-pass and a $585 \mathrm{~nm}$ high-pass filters as the excitation and detection wavelengths, respectively. Fluorescence data were acquired every $60 \mathrm{~s}$ for $30 \mathrm{~min}$ at $37^{\circ} \mathrm{C}$. Efflux activity was quantified by comparing the fluorescence data obtained for mycobacteria under conditions that allow maximum efflux (incubation at $37^{\circ} \mathrm{C}$, in the presence of glucose and absence of $\mathrm{EPI}$ ) against the data from the control tube that contains the EtBr-loaded cells under conditions that inhibit efflux (presence of EPI and no glucose). Thus, the relative fluorescence corresponds to the ratio of fluorescence that remains per unit of time relative to the EtBr-loaded cells $[19,21]$. Each experiment was conducted at least three times and the results obtained did not vary qualitatively. 


\section{5. $\left[{ }^{14} \mathrm{C}\right]$-Erythromycin accumulation assay}

MAC cultures were grown in $7 \mathrm{H} 9 / \mathrm{OADC}$ at $37^{\circ} \mathrm{C}$ until an $\mathrm{OD}_{600}$ of 0.8 . Cells were harvested by centrifugation at $13000 \mathrm{rpm}$ for $3 \mathrm{~min}$, washed once with PBS and the pellet was re-suspended in the same buffer. The $\mathrm{OD}_{600}$ was adjusted to 0.4 with PBS containing glucose at a final concentration of $0.4 \%$ and $10 \mu \mathrm{M}$ of $\left[{ }^{14} \mathrm{C}\right]$-erythromycin (specific activity $50 \mathrm{mCi} / \mathrm{mmol}$ ) was added. The bacterial suspension containing radiolabelled erythromycin was split into two replicate sets: one set of triplicate tubes received $0.05 \mathrm{~mL}$ of an EPI at $0.5 \times$ MIC, whilst the other set of triplicate tubes received an equal volume of PBS. Following incubation at $37^{\circ} \mathrm{C}$ for $16 \mathrm{~h}, 1.0 \mathrm{~mL}$ aliquots were filtered on Whatman GF/C filters. The filters were washed twice with $3.0 \mathrm{~mL}$ of cold 100 $\mathrm{mM}$ lithium chloride-50 $\mathrm{mM}$ potassium phosphate buffer $(\mathrm{pH} 7.0)$, dried overnight at $37^{\circ} \mathrm{C}$ and transferred to scintillation vials containing the liquid scintillation cocktail ULTIMA GOLD F. The counts per minute (CPM) of each triplicate tube of the replicate sets corresponding to $\left[{ }^{14} \mathrm{C}\right]$-erythromycin that remained inside the cells were obtained with the aid of a Beckman LS6500 scintillation counter (Beckman Coulter, Fullerton, CA). The data presented are the average CPM per replicate set of three tubes.

\subsection{Screening for mutations in the 23S rRNA gene associated with macrolide resistance}

Mycobacterial genomic DNA was extracted using a QIAamp DNA Mini Kit (QIAGEN GmbH, Hilden, Germany) according to the manufacturer's instructions. A 420-bp DNA fragment, spanning positions 1886-2305 of domain 
$V$ of the $23 \mathrm{~S}$ rRNA gene, was amplified by polymerase chain reaction (PCR) using primers 23S_FI (TTTAAGCCCCAGTAAACGGC) and 23S_RIII (GTCCAGGTTGAGGGAACCTT) as described previously [22]. The reaction mixture $(50 \mu \mathrm{L})$ contained $2.5 \mathrm{U}$ of Taq polymerase (Fermentas Inc., Ontario, Canada), 1× Taq buffer (Fermentas Inc.), 20 pmol of each primer, 200 mM dNTP and $1.75 \mathrm{mM} \mathrm{MgCl}_{2}$. PCR was conducted in a Mastercycler personal 5332 thermocycler (Eppendorf AG, Hamburg, Germany) and amplification conditions were as follows: DNA denaturation at $94{ }^{\circ} \mathrm{C}$ for 4 min; 35 cycles of denaturation at $94{ }^{\circ} \mathrm{C}$ for $1 \mathrm{~min}$, annealing at $55^{\circ} \mathrm{C}$ for $1 \mathrm{~min}$ and extension at $72^{\circ} \mathrm{C}$ for $1 \mathrm{~min}$; and a final extension at $72{ }^{\circ} \mathrm{C}$ for $10 \mathrm{~min}$. Amplification products were visualised in $1 \%$ agarose gels, purified and sequenced in both strands. Sequences were analysed and aligned using the programs BioEdit version 7.0.9, and ClustalW, respectively, with reference to the 23S rRNA gene of the M. avium 104 genome (GenBank accession no. CP000479.1).

\section{Results}

The MICs for clarithromycin and erythromycin against the identified strains are summarised in Table 1. Among the clinical strains tested, $M$. avium 47/07, $M$. avium 386/08, M. intracellulare 253/07 and M. intracellulare AL2 presented clinically significant resistance to clarithromycin [breakpoints according to CLSI guidelines: susceptible, $\leq 16 \mathrm{mg} / \mathrm{L}$; intermediate, $32 \mathrm{mg} / \mathrm{L}$; and resistant, $\geq 64$ $\mathrm{mg} / \mathrm{L}]$ and a high MIC for erythromycin. This high-level clarithromycin/erythromycin resistance is invariably associated with a mutation 
in adenine 2058 or 2059 in domain $\mathrm{V}$ of the 23S rRNA gene and is the main mechanism of resistance accounting for this phenotype [23-25].

To determine whether the drug susceptibility phenotype of these isolates was affected by the presence of EPIs, the MIC for each antibiotic was determined in the absence and presence of $0.5 \times$ MICs of thioridazine, chlorpromazine and verapamil (Table 2). It is important to note that $0.5 \times \mathrm{MIC}$ of each of the agents listed has no effect on the viability of the organisms (data not shown). This is a condition that must be satisfied if the effect of the EPI on the MIC of an antibiotic is to be exclusively that against the efflux system itself $[19,21]$. As shown by the results presented in Table 1, the EPIs chlorpromazine and thioridazine reduced the MIC of clarithromycin for 12 of the 20 isolates tested. The effects of these EPIs on the MICs of erythromycin were also evident for seven strains. Verapamil promoted a significant reduction in the MICs for clarithromycin and erythromycin in four and eight strains, respectively. These results suggest that MAC strains have one or more chlorpromazine- and thioridazine-sensitive efflux pump(s) that recognise clarithromycin as a substrate. However, in the particular case of the strains with high-level resistance to clarithromycin, the reduction in the MICs promoted by the EPIs does not reach a level of susceptibility, i.e. MIC $\leq 16 \mathrm{mg} / \mathrm{L}$.

Screening for mutations in domain $\mathrm{V}$ of the $23 \mathrm{~S}$ rRNA gene revealed the presence of point mutations in position 2058 in three strains that presented high-level resistance to clarithromycin (M. avium 47/07, A $\rightarrow \mathrm{G}$; $M$. intracellulare 253/07, A $\rightarrow C$; and $M$. intracellulare AL2, A $\rightarrow C$ ). Substitution of the adenine at 
position 2058 by guanine or cytosine has been described in association with high-level resistance to clarithromycin $[22,23,25]$. The other isolate showing phenotypic resistance to clarithromycin (M. avium 386/08), albeit at a lower level, presented a wild-type sequence in this region of the 23S rRNA gene. This phenotype could result from mutation(s) located outside this region or could be due to a different resistance mechanism(s), including efflux.

The efflux activity of MAC reference and clinical strains was assessed by a semi-automated fluorometric method in the presence and absence of the EPIs. As shown in Fig. 1, efflux of EtBr was detected both in reference and clinical strains (represented by M. avium $386 / 08$ and $M$. intracellulare AL2) at $37^{\circ} \mathrm{C}$ in the presence of glucose. Moreover, this efflux activity decreased in the presence of verapamil and thioridazine (Fig. 1). A similar effect was observed with chlorpromazine (data not shown). Whilst both M. avium strains showed similar EtBr efflux activity, for $M$. intracellulare efflux was more evident in the clinical strain whilst only a basal efflux activity was registered for $M$. intracellulare ATCC $13950^{\top}$. These results provide further evidence that efflux activity is involved in resistance to macrolides in both $M$. avium and $M$. intracellulare clinical strains. Evidence for such activity was also provided by studying the retention of radiolabelled erythromycin in order to compare the intracellular accumulation of this antibiotic in the presence or absence of an EPI. As shown in Fig. 2, the presence of thioridazine and verapamil promotes intracellular retention of $\left[{ }^{14} \mathrm{C}\right]$-erythromycin, in accordance with the results obtained for erythromycin MIC determination in the presence and absence of these EPIs (Table 1). These results confirm the previous assumption that at 
least one active efflux system is involved in the extrusion of macrolides and contributes to the resistance of MAC to these drugs.

\section{Discussion}

Mycobacteria belonging to MAC are still the most frequent cause of opportunistic bacterial infection in patients with AIDS. Treatment of MAC disease remains difficult and requires months of multiple therapy, although it has been greatly improved with the introduction of the extended-spectrum macrolides clarithromycin and azithromycin, which are far more effective than other antimicrobial agents against MAC infections [1-4]. However, crossresistance between clarithromycin and azithromycin has been detected and, although monotherapy with clarithromycin (or azithromycin) significantly reduced levels of MAC bacteraemia, it is usually followed by relapses from macrolide-resistant strains. Consequently, other antimycobacterial drugs must be used in combination with clarithromycin to prevent the emergence of macrolide resistance [26].

Efflux of antibiotics has been identified as a relevant contributor to bacterial resistance in clinical practice and is now recognised as an important cause of intrinsic antibiotic resistance in mycobacteria $[12,18,19]$. In this work, we investigated the contribution of active efflux to macrolide resistance in clinical MAC strains isolated from AIDS patients. In these strains, resistance to clarithromycin was significantly reduced in the presence of EPIs such as the calcium-channel inhibitors thioridazine and chlorpromazine as well as the calcium ion influx inhibitor verapamil, which have been shown to inhibit efflux 
activity in M. avium ATCC $25291^{\top}$ [19]. In this work, we have also shown that these EPIs effectively reduce the MIC of clarithromycin for most clinical strains tested. The same EPIs were effective in decreasing efflux from MAC cells loaded with EtBr, a known efflux pump substrate. These efflux assays highlighted the efflux activity in the four high-level resistant MAC strains identified in this study (two M. avium and two M. intracellulare strains), demonstrating that besides the presence of mutations in the 23S rRNA gene in three of these strains, this high-level resistance also results from efflux activity, as already suggested by the reduction of MICs for clarithromycin and erythromycin in the presence of the EPIs (Table 1). Retention of $\left[{ }^{14} \mathrm{C}\right]-$ erythromycin by the same inhibitors further demonstrated that active efflux contributes to MAC resistance to macrolides.

Prolonged exposure to antimycobacterial compounds, such as in MAC therapy, may render the mycobacterial population increasingly resistant by means of increased efflux activity, from which mutants emerge with an increased probability, explaining the relapses from macrolide-resistant strains in patients subjected to monotherapy, especially in AIDS patients where the immune system is weakened; there is thus the need to add other mycobacterial drugs $[10,26]$. Therefore, agents that inhibit mycobacterial efflux pumps not only render the organism more susceptible to an antibiotic but also reduce the probability of selection of spontaneously arising mutants and may become important antimycobacterial therapy adjuvants and a source of new antimycobacterial compounds. 
Acknowledgments: The authors are indebted to the clinicians and laboratory technicians from the hospitals of the Greater Lisbon Area, especially Hospital São Bernardo E.P.E (Setúbal, Portugal).

Funding: This work was partially supported by grants EU-FSE/FEDERPOCI/SAU-MMO/59370/2004 and EU-FSE/FEDERPTDC/BIA-MIC/71280/2006 provided by the Fundação para a Ciência e a Tecnologia (FCT) of Portugal. LR and DM were supported by grants SFRH/BD/24931/2005 and PTDC/BIAMIC/BIC-01/2008, respectively, from FCT, Portugal.

Competing interests: None declared.

Ethical approval: Not required. 


\section{References}

[1] Primm TP, Lucero CA, Falkinham JO 3rd. Health impacts of environmental mycobacteria. Clin Microbiol Rev 2004;17:98-106.

[2] Guthertz LS, Damsker B, Bottone EJ, Ford EG, Midura TF, Janda JM. Mycobacterium avium and Mycobacterium intracellulare infection in patients with and without AIDS. J Infect Dis 1989;160:1037-41.

[3] Griffith DE. Therapy of nontuberculous mycobacterial disease. Curr Opin Infect Dis 2007;20:198-203.

[4] Field SK, Fisher D, Cowie RL. Mycobacterium avium complex pulmonary disease in patients without HIV infection. Chest 2004;126:566-81.

[5] Inderlied CB, Kemper CA, Bermudez LEM. The Mycobacterium avium complex. Clin Microbiol Rev 1993;6:266-310.

[6] Tsang AY, Denner JC, Brennan PJ, McClatchy JK. Clinical and epidemiological importance of typing of Mycobacterium avium complex isolates. J Clin Microbiol 1992;30:479-84.

[7] Yakrus MA, Good RC. Geographic distribution, frequency, and specimen source of Mycobacterium avium complex serotypes isolated from patients with acquired immunodeficiency syndrome. J Clin Microbiol 1990;28:926-9.

[8] Turenne CY, Wallace R Jr, Behr MA. Mycobacterium avium in the postgenomic era. Clin Microbiol Rev 2007;20:205-29.

[9] Jarlier V, Nikaido H. Mycobacterial cell wall: structure and role in natural resistance to antibiotics. FEMS Microbiol Lett 1994;123:11-8.

[10] Tomioka H. Present status and future prospects of chemotherapeutics for intractable infections due to Mycobacterium avium complex. Curr Drug Discov Technol 2004;1:255-68. 
[11] Clinical and Laboratory Standards Institute. Susceptibility testing of mycobacteria, Nocardiae, and other aerobic actinomycetes; approved standard. Vol. 23, No. 18. Document M24-A. Wayne, PA: CLSI; 2003.

[12] Viveiros M, Leandro C, Amaral L. Mycobacterial efflux pumps and chemotherapeutic implications. Int J Antimicrob Agents 2003;22:274-8.

[13] De Rossi E, Ainsa JA, Riccardi G. Role of mycobacterial efflux transporters in drug resistance: an unresolved question. FEMS Microbiol Rev 2006;30:36-52.

[14] Doucet-Populaire F, Buriankova K, Weiser J, Pernodet JL. Natural and acquired macrolide resistance in mycobacteria. Curr Drug Targets Infect Disord 2002;2:355-70.

[15] Amaral L, Martins M, Viveiros M. Enhanced killing of intracellular multidrug-resistant Mycobacterium tuberculosis by compounds that affect the activity of efflux pumps. J Antimicrob Chemother 2007;59:1237-46.

[16] Silva PE, Bigi F, Santangelo MP, Romano MI, Martín C, Cataldi A, et al. Characterization of P55, a multidrug efflux pump in Mycobacterium bovis and Mycobacterium tuberculosis. Antimicrob Agents Chemother $2001 ; 45: 800-4$.

[17] Viveiros M, Portugal I, Bettencourt R, Victor TC, Jordaan AM, Leandro C, et al. Isoniazid-induced transient high-level resistance in Mycobacterium tuberculosis. Antimicrob Agents Chemother 2001;46:2804-10.

[18] Viveiros M, Martins M, Couto I, Kristiansen JE, Molnar J, Amaral L. The in vitro activity of phenothiazines against Mycobacterium avium: potential of thioridazine for therapy of the co-infected AIDS patient. In Vivo 2005;19:733-6. 
[19] Rodrigues L, Wagner D, Viveiros M, Sampaio D, Couto I, Vavra M, et al. Thioridazine and chlorpromazine inhibition of ethidium bromide efflux in Mycobacterium avium and Mycobacterium smegmatis. J Antimicrob Chemother 2008;61:1076-82.

[20] Kent PT, Kubica GP. Public health mycobacteriology: a guide for the level III laboratory. Atlanta, GA: US Centers for Disease Control and Prevention, US Department of Health and Human Services; 1985.

[21] Viveiros M, Martins A, Paixão L, Rodrigues L, Martins M, Couto I, et al. Demonstration of intrinsic efflux activity of Escherichia coli K-12 AG100 by an automated ethidium bromide method. Int $\mathrm{J}$ Antimicrob Agents $2008 ; 31: 458-62$.

[22] Jamal MA, Maeda S, Nakata N, Kai M, Fukuchi K, Kashiwabara Y, et al. Molecular basis of clarithromycin resistance in Mycobacterium aviumintracellulare complex. Tuber Lung Dis 2000;80:1-4.

[23] Nash KA, Inderlied CB. Genetic basis of macrolide resistance in Mycobacterium avium isolated from patients with disseminated disease. Antimicrob Agents Chemother 1995;39:2625-30.

[24] Meier A, Heifets L, Wallace RJ Jr, Zhang Y, Brown BA, Sander P, et al. Molecular mechanisms of clarithromycin resistance in Mycobacterium avium: observation of multiple $23 \mathrm{~S}$ rDNA mutations in a clonal population. J Infect Dis 1996;174:354-60.

[25] Griffith DE, Brown-Elliott BA, Langsjoen B, Zhang Y, Pan X, Girard W, et al. Clinical and molecular analysis of macrolide resistance in Mycobacterium avium complex lung disease. Am J Respir Crit Care Med 2006;174:928-34. 
[26] Heifets LB. Clarithromycin against Mycobacterium avium complex infections. Tuber Lung Dis 1996;77:19-26. 
Fig. 1. Efflux of ethidium bromide (EtBr) by Mycobacterium avium ATCC $25291^{\top}$, Mycobacterium intracellulare ATCC $13950^{\top}$ and the clinical strains $M$. avium 386/08 and M. intracellulare AL2. Assays were conducted at $37^{\circ} \mathrm{C}$, with or without an efflux pump inhibitor (EPI). Relative fluorescence was obtained by normalisation of data against the conditions of no efflux (presence of EPI and no glucose). Efflux of EtBr was inhibited by verapamil (VP) and thioridazine (TZ) used at $0.5 \times$ the minimum inhibitory concentration.

Fig. 2. Retention of $\left[{ }^{14} \mathrm{C}\right]$-erythromycin (Ery) by Mycobacterium avium complex reference and clinical strains. Intracellular accumulation of $\left[{ }^{14} \mathrm{C}\right]$-Ery was determined in the presence and absence of verapamil (VP) or thioridazine (TZ) at $0.5 \times$ the minimum inhibitory concentration. Values [expressed as counts per minute $(\mathrm{CPM})]$ are the average of three replicate tubes. Error bars indicate standard deviations. 


\section{Table 1}

Effect of the efflux pump inhibitors (EPIs) thioridazine (TDZ), chlorpromazine (CPZ) and verapamil (VER) on the minimum inhibitory concentrations (MICs) of clarithromycin and erythromycin against Mycobacterium avium complex strains a

\begin{tabular}{|c|c|c|c|c|c|c|c|c|}
\hline \multirow[t]{3}{*}{ Strain } & \multicolumn{8}{|c|}{$\operatorname{MIC}(\mathrm{mg} / \mathrm{L})^{\mathrm{b}}$} \\
\hline & \multicolumn{4}{|c|}{ Clarithromycin } & \multicolumn{4}{|c|}{ Erythromycin } \\
\hline & No EPI & TDZ & CPZ & VER & No EPI & TDZ & CPZ & VER \\
\hline M. avium ATCC $25291^{\top}$ & 4 & 2 & 2 & 2 & 16 & 0.5 & 0.5 & 4 \\
\hline M. avium 104 & 8 & 8 & 8 & 8 & 256 & 256 & 256 & 256 \\
\hline M. avium HSB1 & 8 & 2 & 2 & 4 & 256 & 256 & 256 & 256 \\
\hline M. avium HSB2 & 8 & 2 & 2 & 8 & 256 & 256 & 256 & 256 \\
\hline M. avium HSB3 & 8 & 2 & 2 & 8 & 256 & 64 & 16 & 128 \\
\hline M. avium HSB4 & 8 & 1 & 1 & 8 & 256 & 128 & 128 & 256 \\
\hline M. avium HSB5 & 8 & 2 & 2 & 2 & 256 & 256 & 256 & 256 \\
\hline M. avium HSB6 & 8 & 2 & 2 & 8 & 256 & 256 & 256 & 256 \\
\hline M. avium AL1 & 8 & 2 & 1 & 1 & 128 & 64 & 16 & 16 \\
\hline M. avium 47/07 & 1024 & 1024 & 1024 & 512 & 512 & 256 & 512 & 128 \\
\hline M. avium 386/08 & 512 & 512 & 128 & 512 & 1024 & 256 & 256 & 512 \\
\hline M. intracellulare ATCC $13950^{\top}$ & 0.25 & 0.25 & 0.25 & 0.25 & 0.06 & 0.06 & 0.06 & 0.06 \\
\hline M. intracellulare $101 / 07$ & 8 & 8 & 4 & 8 & 256 & 256 & 256 & 64 \\
\hline M. intracellulare $278 / 07$ & 8 & 8 & 8 & 8 & 256 & 16 & 16 & 256 \\
\hline M. intracellulare 308/07 & 1 & 0.5 & 0.5 & 1 & 256 & 256 & 256 & 16 \\
\hline M. intracellulare 421/07 & 1 & 0.5 & 0.5 & 1 & 256 & 256 & 256 & 256 \\
\hline M. intracellulare $30 / 08$ & 1 & 0.25 & 0.5 & 0.25 & 256 & 256 & 256 & 64 \\
\hline M. intracellulare $92 / 08$ & 2 & 0.5 & 1 & 0.125 & 256 & 256 & 128 & 256 \\
\hline M. intracellulare 253/07 & 1024 & 1024 & 256 & 1024 & 2048 & 1094 & 512 & 256 \\
\hline M. intracellulare AL2 & 2048 & 256 & 2048 & 1024 & 2048 & 256 & 1094 & 256 \\
\hline
\end{tabular}

${ }^{a}$ EPIs were used at $0.5 \times$ MIC. A four-fold reduction was considered to denote a significant synergistic effect between the antibiotic and the EPI and is identified in bold. 
${ }^{\mathrm{b}}$ Breakpoints for clarithromycin MIC determination by microdilution in Middlebrook $7 \mathrm{H} 9$ broth ( $\mathrm{pH}$ 6.8) were as follows: susceptible, $\leq 16 \mathrm{mg} / \mathrm{L}$; intermediate, $32 \mathrm{mg} / \mathrm{L}$; resistant, $\geq 64 \mathrm{mg} / \mathrm{L}$ [11]. 


\section{Table 2}

Minimum inhibitory concentrations (MICs) of ethidium bromide (EtBr) and the efflux pump inhibitors thioridazine (TDZ), chlorpromazine (CPZ) and verapamil (VER) determined for Mycobacterium avium complex clinical and reference strains

\begin{tabular}{lllll}
\hline Strain & \multicolumn{3}{l}{ MIC (mg/L) } & \\
\cline { 2 - 5 } & TDZ & CPZ & VER & EtBr \\
\hline M. avium ATCC 25291 & 20 & 25 & 800 & 6.25 \\
M. avium 104 & 25 & 25 & 500 & 6.25 \\
M. avium HSB1 & 25 & 25 & 1000 & 16 \\
M. avium HSB2 & 25 & 25 & 500 & 8 \\
M. avium HSB3 & 25 & 25 & 1000 & 16 \\
M. avium HSB4 & 25 & 25 & 1000 & 16 \\
M. avium HSB5 & 6.25 & 25 & 1000 & 8 \\
M. avium HSB6 & 25 & 25 & 500 & 8 \\
M. avium AL1 & 10 & 25 & 500 & 6.25 \\
M. avium 47/07 & 12.5 & 12.5 & 500 & 12.5 \\
M. avium 386/08 & 25 & 12.5 & 1000 & 12.5 \\
M. intracellulare ATCC 13950 & 12.5 & 50 & 1000 & 2 \\
M. intracellulare 101/07 & 12.5 & 12.5 & 500 & 12.5 \\
M. intracellulare 278/07 & 12.5 & 12.5 & 500 & 6.25 \\
M. intracellulare 308/07 & 12.5 & 12.5 & 500 & 12.5 \\
M. intracellulare 421/07 & 12.5 & 12.5 & 500 & 12.5 \\
M. intracellulare 30/08 & 12.5 & 12.5 & 500 & 12.5 \\
M. intracellulare 92/08 & 12.5 & 12.5 & 500 & 12.5 \\
M. intracellulare 253/07 & 6.25 & 12.5 & 500 & 4 \\
M. intracellulare AL2 & 6.25 & 12.5 & 500 & 4 \\
\hline
\end{tabular}



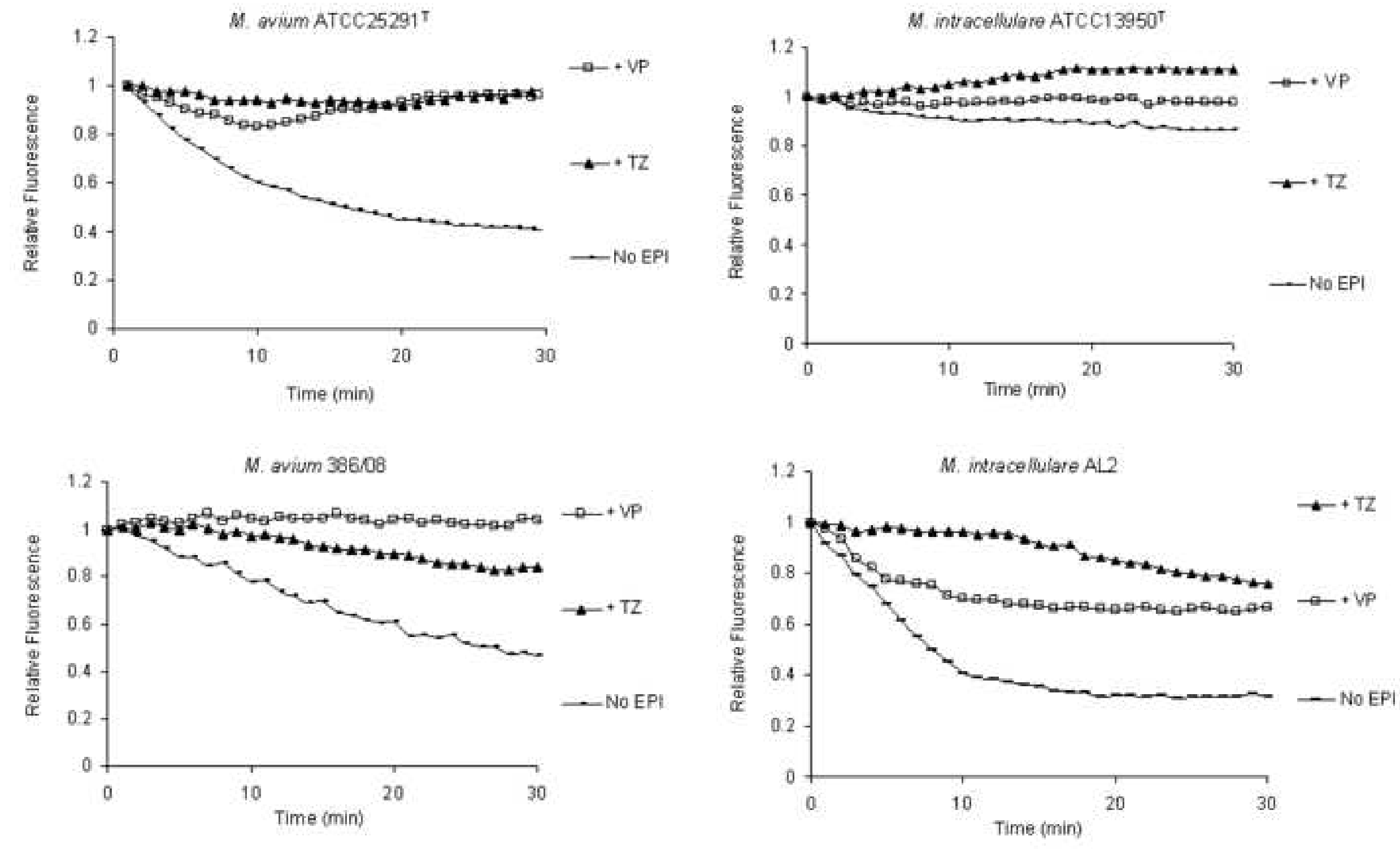


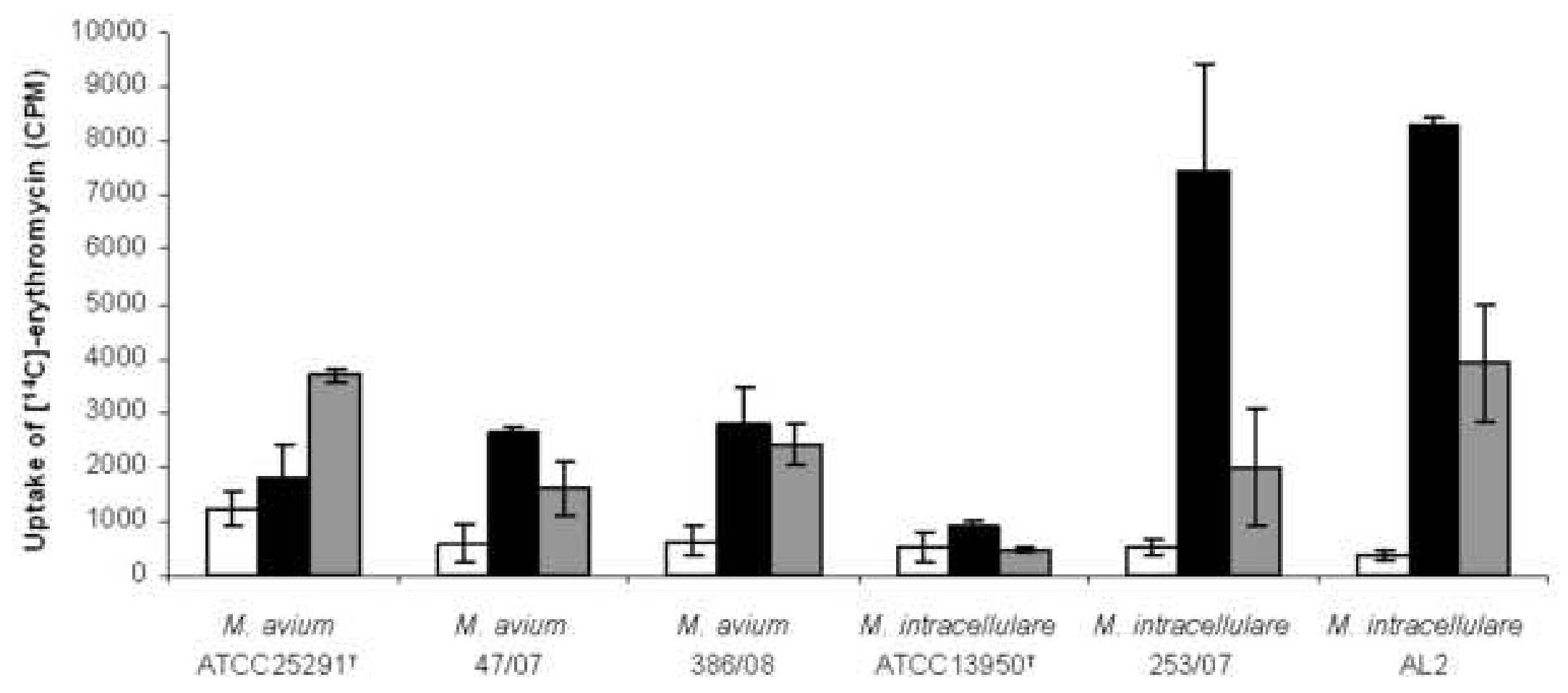

口Ery

ary + VP

口Ery + TZ 